\title{
Caraterização e distribuiç̧ão espacial dos acidentes de trânsito não fatais
}

\section{Space characterization and distribution of non-fatal traffic accidents}

\author{
Willian Augusto de Melo** (1), Renata Rodrigues Mendonça ${ }^{1 *}$ (1) \\ 'Centro de Ciências da Saúde da Universidade Estadual do Paraná (UNESPAR) - Paranavaí, PR, Brasil.
}

Como citar: Melo WA, Mendonça RR. Caraterização e distribuição espacial dos acidentes de trânsito não fatais. Cad Saúde Colet, 2021;29(1):1-12. https://doi.org/10.1590/1414-462X202129010364

\section{Resumo}

Introdução: Acidentes de trânsito geram mortes e sequelas que impactam a qualidade de vida das pessoas. Objetivo: Caracterizar e distribuir espacialmente os acidentes de trânsito não fatais ocorridos em uma metrópole do noroeste paranaense. Método: Trata-se de um estudo ecológico e transversal, com informações oriundas de uma amostragem probabilística de 423 vítimas procedentes dos Boletins de Ocorrência de Acidente de Trânsito (BOAT) do $4^{\circ}$ Batalhão da Polícia Militar de Maringá, Paraná. Verificaram-se distribuições percentuais com respectivos intervalos de confiança para as variáveis qualitativas e medidas de tendência central para as quantitativas. A produção cartográfica foi realizada pelos softwares Exce $^{\circledR}$ e $Q G I S^{\circledR}$ 2.6.1. Resultados: Predominaram vítimas do sexo masculino (85,0\%), com idade inferior a 30 anos (58,4\%), possuíam ocupação remunerada (92,3\%), 55,0\% eram motociclistas, 89,4\% com tempo de habilitação superior a dois anos e 59,3\% foram hospitalizadas devido às lesões. Quanto à distribuição espacial, os bairros Centro e seus arredores, como Alvorada, Zona 7 e Vila Morangueira, apresentaram maior número de ocorrências. Conclusão: Características das vítimas: homens jovens menores de 30 anos, trabalhadores, motociclistas com ocorrências predominantes na região central e arredores. Há necessidade de intervenções para reduzir e identificar pontos críticos de localização e suas consequências mais graves.

Palavras-chave: acidente de trânsito; causas externas; adulto jovem; epidemiologia.

\begin{abstract}
Background:Traffic accidents result in deaths and injuries that impact people's quality of life. Objective: The objective of this study aimed to characterize and spatially distribute the non-fatal traffic accidents in a metropolis in the Northwest of Paraná. Method: This work was characterized by an ecological and cross-sectional study, with information from a probability sampling of 423 victims from the Traffic Accident Reporting Bulletins (in Portuguese Boletins de Ocorrência de Acidente de Trânsito (BOAT)) of the 4th Military Police Battalion of Maringá, in the state of Paraná. Percent distributions with respective confidence intervals for the qualitative variables, as well as measures of central tendency for the quantitative variables were verified. Cartographic production was carried out with the aid of Excel ${ }^{\circledR}$ and $Q G I S^{\circledR} 2.6 .1$ software. Results: There was a predominance of male victims (85.0\%), under the age of 30 (58.4\%), including paying jobs $(92.3 \%)$, in which $55.0 \%$ of them were motorcyclists, $89.4 \%$ of drivers with up two years of driving experience, and $59.3 \%$ were hospitalized due to injuries. Regarding the spatial distribution, the central districts of the city and its neighborhoods, such as, Alvorada, Zona 7 and Vila Morangueira, presented the largest number of occurrences. Conclusion: Characteristics of the victims: young men under 30, workers, motorcyclists with predominance of occurrence rates in the central region and neighborhoods. Interventions need to be done to reduce and identify the location of critical points and their most serious consequences.
\end{abstract}

Keywords: traffic accidents; external causes; young adult; epidemiology.

Este é um artigo publicado em acesso aberto (Open Access) sob a licença Creative Commons Attribution, que permite uso, distribuição e reprodução em qualquer meio, sem restrições desde que o trabalho original seja corretamente citado.
Trabalho realizado no 4 Batalhão da Polícia Militar do Paraná, localizado no município de Maringá (PR), Brasil. Correspondência:Willian Augusto de Melo. E-mail: willian.enfer@gmail.com

Fonte de financiamento: nenhuma.

Conflito de interesses: nada a declarar.

Recebido em: Out. 03, 2017. Aprovado em: Jan. 07, 2020 


\section{INTRODUÇÃO}

Acidente de trânsito (AT) foi definido, pelo Instituto de Pesquisa Econômica Aplicada (IPEA) e Departamento Nacional de Trânsito (DENATRAN), como evento ocorrido em via pública, inclusive calçadas, decorrente do trânsito de veículos e pessoas, que resulta em danos humanos e materiais. Compreende colisões entre veículos, choques com objetos fixos, capotamentos, tombamentos, atropelamentos e queda de pedestres e ciclistas'.

Ao redor do mundo, 50 milhões de pessoas ficam feridas e aproximadamente 1,2 milhão morre a cada ano devido aos $\mathrm{AT}^{2}$. Os AT no Brasil matam aproximadamente 43 mil pessoas por ano segundo os dados do Departamento de Informática do Sistema Único de Saúde (DATASUS), do Ministério da Saúde (MS), evidenciando uma das principais causas de morte no País. As mortes nas rodovias federais representam cerca de 20\% (8.227 mortes em 2014), com cerca de 30 mil feridos graves por ano, com impactos diretamente relacionados com as verbas públicas e a renda das famílias atingidas ${ }^{3}$.

O Brasil é o quinto país com o maior número de acidentes de trânsito, segundo levantamento da Organização Mundial de Saúde (OMS) e Organização Pan-Americana de Saúde (OPAS). De acordo com o Ministério da Saúde, somente em 2014, mais de 40 mil mortes foram registradas por acidentes de trânsito e outras 170 mil internações foram contabilizadas no Sistema Único de Saúde (SUS), cerca de 117 mortes por dia, o que representa cinco mortes por hora, sendo 10.279 mortes em decorrência de acidentes com motocicleta ${ }^{4}$. Na última década, houve um aumento de $505 \%$ dos acidentes com motocicleta contra um crescimento de $57,2 \%$ dos acidentes com automóveis. O anuário estatístico do DETRAN/PR (2015) apresentou 21.124 casos registrados de acidentes de trânsito com vítimas no Estado do Paraná envolvendo motocicleta, perdendo apenas para o número de acidentes automobilísticos com vítimas que contabilizou 31.063 casos $^{5}$.

As mortes ou as sequelas que permanecem em quem sobrevive aos AT geram um impacto que afeta direta e indiretamente a qualidade de vida e as condições de saúde dos grupos populacionais expostos a essas causas. Além disso, representam um grande problema de saúde pública a ser enfrentado em todo o mundo, atingindo um número muito maior de pessoas indiretamente, além de que seus efeitos ultrapassam o sofrimento individual e coletivo, incidindo na cultura e no modo de viver das pessoas ${ }^{6}$.

Estudos apontam que o tempo decorrido entre o acidente e o atendimento hospitalar é um fator crucial para diminuir a mortalidade e a ocorrência de sequelas, uma vez que $40 \%$ dos óbitos ocorrem na fase pré-hospitalar. Em face destas características, para o atendimento neste cenário, há a necessidade de profissionais capacitados. Destaca-se que, no Brasil, a implantação dos serviços de atendimento pré-hospitalar ocorreu no início da década de 90 , o qual passou a ser denominado de Serviço de Atenção Móvel de Urgência (SAMU), a partir do Plano Nacional de Atendimento à Urgência e Emergência em 20037

Neste novo contexto, a área de urgência e emergência tem exigidó dos enfermeiros uma nova forma de atuação, tornando-se necessário o rompimento com um modelo de trabalho tradicional, cujas tarefas, em sua maioria, são baseadas no modelo de assistência biomédico e centradas em rotinas e tarefas, que não têm dado solução às necessidades humanas do paciente crítico. Segundo a legislação, que dispõe sobre a regulamentação da Assistência de Enfermagem em Atendimento Pré-Hospitalar e demais situações relacionadas com o Suporte Básico e Suporte Avançado de Vida, somente o enfermeiro poderá realizar procedimentos de alta complexidade e prestar assistência de enfermagem em unidades móveis de UTI e Suporte Avançado de Vida?.

Os jovens têm sido constantemente identificados como as principais vítimas de AT o que pode estar associado a fatores como inexperiência, busca de emoções, prazer em experimentar situações de risco, impulsividade e abuso de substâncias psicoativas e álcool’ .

Um aspecto relevante que deve ser considerado é a respeito da insuficiência de informações sobre causas externas no Brasil, pelo fato de que os dois sistemas, mortalidade e morbidade, fornecem uma descrição sucinta dos acidentes e violências, sem fornecer informações detalhadas do perfil da vítima e do provável autor da agressão nos casos de violências ${ }^{6}$.

Essas três categorias, pedestres, motociclistas e ocupantes de automóveis, somadas representam, ao longo de todo o período, em torno de $90 \%$ do total de mortes no trânsito do País ${ }^{10}$. 
O aumento do número de mortes e a manutenção das taxas de mortalidade e hospitalizações sugerem que o Brasil não está na direção correta no combate aos AT, mesmo que, no decorrer dos anos, fatores como a rede informatizada dos dados, facilidades de compra e melhora tecnológica de equipamentos (bafômetros, radares, lombadas eletrônicas e outros), maior segurança dos automóveis, desenvolvimento da engenharia de tráfego e serviços de emergência pré-hospitalar tenham contribuído para tentar diminuir as taxas de mortalidade e morbidade ${ }^{11}$.

Os AT estão frequentemente associados aos grandes centros urbanos eàs grandes autopistas, porém as estatísticas oficiais mostram que muitos ocorrem também nas pequenas e médias cidades no interior. Na medida em que aumentam as necessidades de deslocamento, em função do aumento da população, da mudança de hábitos, econômica, ou do aumento da renda, o espaço urbano tem tendência a sofrer adaptações de forma desconexa ${ }^{12}$.

Técnicas de distribuição ou análise espacial são importantes ferramentas que auxiliam a subsidiar pesquisadores com dados precisos quanto à localização dos pontos críticos de acidentes. Isto permite planejamento para intervenções de engenharia do tráfego, atualizar o fluxo de funcionamento viário vigente, nortear o planejamento e gestão do trânsito e das ações de modelos de assistência em saúde efetivos às vítimas ${ }^{13}$.

As novas geotecnologias e a aplicação de estatística espacial possibilitaram criar diagnósticos sobre o comportamento dos acidentes de trânsito, possibilitando comparar estatísticas dos fatos no tempo e no espaço, revelando a evolução do problema e identificando e localizando o grau de gravidade no interior do município ${ }^{12}$.

Este estudo justifica-se pelo fato de que o conhecimento georreferenciado pode estabelecer análises geográficas quanto a características e distribuição espacial dos acidentes de trânsito. Também pode identificar a ocorrência de padrões de agrupamentos, ou mesmo de disposições aleatórias ou regulares das ocorrências no perímetro urbano municipal, possibilitando atuações específicas e pontuais para controle e redução das morbidades e mortalidade decorrente de AT. Com base nestas considerações, este estudo teve por objetivo caracterizar e distribuir espacialmente os AT de vítimas não fatais ocorridos em uma metrópole do noroeste do Paraná, no período de 2013.

\section{MÉTODO}

Trata-se de um estudo ecológico, descritivo e transversal sobre vítimas não fatais de acidentes de trânsito. $O$ universo das vítimas não fatais no ano de 2013 foi de 5.180 casos. As informações foram obtidas por meio dos Boletins de Ocorrência de Acidente de Trânsito (BOAT) coletadas do $4^{\circ}$ Batalhão da Polícia Militar do Paraná localizado em Maringá-PR. Estes boletins de ocorrência foram selecionados por meio de técnica de amostragem probabilística randomizada, adotando o erro padrão amostral de $5 \%$, sendo acrescidos $10 \%$ para compensar eventuais perdas por ilegibilidade ou formulários não preenchidos, resultando em 423 BOAT.

Foram incluídas as variáveis sociodemográficas como sexo; idade categorizada em: 15 a 29 anos e acima de 29 anos; o estado civil foi categorizado com companheiro (casados ou união estável) e sem companheiros (viúvos, solteiros, separados e divorciados); a raça/cor categorizada em branca e não branca, nesta última incluíram-se as subcategorias preto, pardo, amarelo e indígena; a ocupação foi categorizada como remunerada (emprego formal com renda mensal) e não remunerada (com ou sem atividade não remunerada); a escolaridade foi categorizada em dois períodos: até oito anos de estudo (ensino fundamental incompleto ou completo) e oito anos ou mais de estudos (ensino médio e superior incompleto ou completo); local de residência categorizado em município de origem (Maringá) e outros municípios; e tempo de habilitação ( $<2$ anos, 2 a 5 anos, 6 a 10 anos, 11 anos ou mais e sem habilitação).

As variáveis relacionadas ao veículo e ocorrência: tipo de veículo (bicicleta, caminhão, camionete, automóvel, motocicleta, ônibus, patinete motorizado, trator); presença de avarias (sim/não); situação de veículo (em movimento, estacionado, parado); parte do veículo avariada (central, frontal central, frontal lateral, frontal média, frontal, lateral, média esquerda, pintura, póstero esquerdo, traseira, não preenchido); classificação do tipo de acidente (abalroamento lateral, 
abalroamento transversal, acidente complexo, animal atropelado, atropelamento, capotamento, choque, colisão frontal, colisão traseira, engavetamento, queda de veículo, queda de moto, queda de passageiro).

As variáveis relacionadas à ocorrência e cenário dos acidentes de trânsito foram: dias da semana (domingo a sábado), horário da ocorrência (manhã, tarde, noite ou madrugada), atendimento pré-hospitalar (sim/não), hospitalização (público, privado, não hospitalizado).

Para a descrição dos resultados, foi utilizada a estatística descritiva, medidas de tendência central para variáveis quantitativas e medidas proporcionais com seus respectivos intervalos de confiança de $95 \%$ para variáveis qualitativas. As análises foram efetivadas pelos softwares Excel ${ }^{\circledR}$ conforme respectivas categorizações.

Para realização da distribuição espacial, foram identificadas as medidas de coordenadas (latitude e longitude) através do Google Maps de todos os locais de ocorrência dos acidentes não fatais. A base cartográfica municipal, formada por rede viária foi disponibilizada pelo site da Prefeitura Municipal de Maringá-PR e pelo Instituto Brasileiro de Geografia e Estatística (IBGE). A compilação dos resultados e a produção cartográfica foram realizadas com auxílio do software QGIS 2.6.1, que é um software livre/open source multiplataforma de Sistema de Georreferenciamento (GIS) que provê visualização, edição e análise de dados georreferenciados.

O estudo foi aprovado pelo Comitê de Ética e Pesquisa da Universidade Estadual de Maringá (UEM) conforme preceitos éticos da resolução n 466/2012 do Conselho Nacional de Saúde/Ministério da Saúde através do parecer 170.715/2012.

\section{RESULTADOS}

Com relação às características sociodemográficas das vítimas de acidentes de trânsito, prevaleceu o sexo masculino com 358 casos $(85,0 \%)$ de faixa etária entre 15 e 29 anos (58,4\%), sendo a idade média de 32,5 anos $\pm 11,9$ (desvio padrão) (Tabela 1).

As vítimas com estado civil "sem companheiro" configuraram $51,3 \%$ dos casos. No que se refere à escolaridade, $68,3 \%$ possuíam boa escolaridade, ou seja, cursaram o ensino médio ou superior completo ou incompleto, representando oito anos ou mais de estudos.

Dentre os AT, observou-se maior proporção de ocorrências envolvendo motocicletas (231 casos, 55,0\%), sendo válido destacar uma proporção considerável de acidentes envolvendo automóveis (36,0\%), e, nestes, os danos mais frequentes foram na parte frontal, que, ao considerar suas variações, frontal central, lateral e média, totalizaram $57,6 \%$ das ocorrências, sendo ocasionados predominantemente pelo abalroamento transversal (38,3\%) (Tabela 2).

A respeito do atendimento pré-hospitalar, 59,4\% das vítimas necessitaram deste serviço, sendo o Sistema Integrado de Atendimento a Traumas e Emergências (SIATE) a unidade de atendimento móvel responsável pela totalidade das chamadas. Já a hospitalização ocorreu conforme a gravidade dos casos e disponibilidade de vagas, atingindo 59,3\% das vítimas. As unidades hospitalares privadas, prestadoras de serviço para o Sistema Único de Saúde, receberam maior número de encaminhamentos (58,3\%) (Tabela 2).

Os AT transcorreram com frequências similares para cada dia da semana, porém notouse incremento considerável aos sábados quando observado de forma isolada (16,4\%). Com relação ao horário, observaram-se mais ocorrências no período vespertino $(37,1 \%)$, seguido do período matutino (30,5\%)(Tabela 3).

Em relação ao tempo de habilitação dos condutores envolvidos, destacaram- se aqueles com 11 anos ou mais (34,1\%), e os motoristas com dois anos ou mais totalizaram 59,3\% (Tabela 3).

A Figura 1 apresenta a distribuição do número de AT por bairros. As áreas com maior número de ocorrência foram os bairros Alvorada, Zona 7,Vila Morangueira e Centro, respectivamente. As áreas com maior intensidade ficaram localizadas próximo ao centro da cidade. 
Tabela 1. Caracterização das vítimas não fatais de acidentes de trânsito segundo variáveis sociodemográficas. Maringá - PR, 2013.

\begin{tabular}{|c|c|c|c|}
\hline Variáveis Sociodemográficas & $\mathbf{N}$ & $\%$ & $95 \%$ IC* \\
\hline \multicolumn{4}{|l|}{ Sexo $(n=421)$} \\
\hline Masculino & 358 & 85,0 & $(81,31-88,12)$ \\
\hline Feminino & 63 & 15,0 & $(11,87-18,68)$ \\
\hline \multicolumn{4}{|l|}{ Idade $(n=418)$} \\
\hline 15 a 29 anos & 244 & 58,4 & $(53,59-63,00)$ \\
\hline 30 ou mais anos & 174 & 41,6 & $(36,99-46,40)$ \\
\hline \multicolumn{4}{|l|}{ Estado Civil ( $n=413)$} \\
\hline Com Companheiro & 201 & 48,7 & $(43,88-53,47)$ \\
\hline Sem Companheiro & 212 & 51,3 & $(46,52-56,11)$ \\
\hline \multicolumn{4}{|l|}{ Raça/Cor } \\
\hline \multicolumn{4}{|l|}{ Branca } \\
\hline \multicolumn{4}{|l|}{ Não branca } \\
\hline \multicolumn{4}{|l|}{ Ocupação (n=403) } \\
\hline Remunerada & 372 & 92,3 & $(89,28-94,52)$ \\
\hline Não Remunerada & 31 & 7,7 & $(5,47-10,71)$ \\
\hline \multicolumn{4}{|l|}{ Escolaridade $(n=407)$} \\
\hline Ensino Fundamental Completo & 72 & 17,7 & $(14,29-21,69)$ \\
\hline Ensino Fundamental Incompleto & 57 & 14,0 & $(10,96-17,71)$ \\
\hline Ensino Médio Completo & 142 & 34,9 & $(30,41-39,64)$ \\
\hline Ensino Médio Incompleto & 38 & 9,3 & $(6,87-12,55)$ \\
\hline Ensino Superior Completo & 59 & 14,5 & $(11,40-18,24)$ \\
\hline Ensino Superior Incompleto & 39 & 9,6 & $(7,08-12,83)$ \\
\hline \multicolumn{4}{|l|}{ Local de Residência ( $n=417)$} \\
\hline Maringá-PR & 373 & 89,4 & $(86,13-92,04)$ \\
\hline Outros municípios & 44 & 10,6 & $(7,95-13,86)$ \\
\hline \multicolumn{4}{|l|}{ Tempo de habilitação $(n=423)$} \\
\hline$<2$ anos & 45 & 10,6 & $(8,04-13,93)$ \\
\hline 2 a 5 anos & 78 & 18,4 & $(15,03-22,41)$ \\
\hline 6 a 10 anos & 94 & 22,2 & $(18,52-26,42)$ \\
\hline 11 anos ou mais & 144 & 34,1 & $(29,68-38,68)$ \\
\hline Sem habilitação & 62 & 14,7 & $(11,60-18,34)$ \\
\hline
\end{tabular}

* IC - Intervalo de Confiança de 95\%. 
Tabela 2. Distribuição dos acidentes de trânsito não fatais segundo variáveis relacionadas ao veículo envolvido. Maringá - PR, 2013.

\begin{tabular}{|c|c|c|c|}
\hline Variáveis & $\mathbf{N}$ & $\%$ & $95 \%$ IC* \\
\hline \multicolumn{4}{|l|}{ Tipo de Veículo ( $n=420$ ) } \\
\hline Bicicleta & 8 & 1,9 & $(0,96-3,71)$ \\
\hline Caminhão & 7 & 1,7 & $(0,80-3,39)$ \\
\hline Camionete & 5 & 1,2 & $(0,50-2,75)$ \\
\hline Automóvel & 151 & 36,0 & $(31,50-40,64)$ \\
\hline Motocicleta & 231 & 55,0 & $(50,21-59,69)$ \\
\hline Ônibus & 16 & 3,8 & $(2,35-6,09)$ \\
\hline Patinete Motorizado & 1 & 0,2 & $(0,04-1,33)$ \\
\hline Trator & 1 & 0,2 & $(0,04-1,33)$ \\
\hline \multicolumn{4}{|c|}{ Presença de avarias $(n=411)$} \\
\hline Sim & 388 & 94,4 & $(91,74-96,24)$ \\
\hline Não & 23 & 5,6 & $(3,75-8,25)$ \\
\hline \multicolumn{4}{|c|}{ Situação do veículo ( $n=412$ ) } \\
\hline Em movimento & 388 & 94,2 & $(91,47-96,05)$ \\
\hline Estacionado & 1 & 0,2 & $(0,04-1,36)$ \\
\hline Parado & 23 & 5,6 & $(3,74-8,23)$ \\
\hline \multicolumn{4}{|c|}{ Parte do veículo avariada $(\mathrm{n}=320)$} \\
\hline Central & 3 & 0,9 & $(0,31-2,71)$ \\
\hline Frontal Central & 5 & 1,6 & $(0,66-3,60)$ \\
\hline Frontal Lateral & 23 & 7,2 & $(4,83-10,55)$ \\
\hline Frontal Média & 8 & 2,5 & $(1,27-4,85)$ \\
\hline Frontal & 148 & 46,3 & $(40,86-51,72)$ \\
\hline Lateral & 51 & 15,9 & $(12,33-20,34)$ \\
\hline Média Esquerda & 1 & 0,3 & $(0,05-1,74)$ \\
\hline Média Direita & 4 & 1,3 & $(0,48-3,16)$ \\
\hline Pintura & 44 & 13,8 & $(10,44-17,95)$ \\
\hline Póstero Esquerdo & 9 & 2,8 & $(1,48-5,25)$ \\
\hline Traseira & 24 & 7,5 & $(5,09-10,91)$ \\
\hline \multicolumn{4}{|l|}{ Não preenchido } \\
\hline \multicolumn{4}{|c|}{ Classificação tipo de acidente $(n=420)$} \\
\hline Abalroamento Lateral & 53 & 12,6 & $(9,77-16,13)$ \\
\hline Abalroamento Transversal & 161 & 38,3 & $(33,80-43,06)$ \\
\hline Acidente Complexo & 37 & 8,8 & $(6,45-11,90)$ \\
\hline
\end{tabular}

* IC - Intervalo de Confiança de 95\%. 
Tabela 2. Continua...

\begin{tabular}{|c|c|c|c|}
\hline Variáveis & $\mathbf{N}$ & $\%$ & $95 \%$ IC* \\
\hline Animal Atropelado & 15 & 3,6 & $(2,17-5,80)$ \\
\hline Atropelamento & 29 & 6,9 & $(4,85-9,74)$ \\
\hline Capotamento & 2 & 0,5 & $(0,13-1,71)$ \\
\hline Choque & 29 & 6,9 & $(4,85-9,74)$ \\
\hline Colisão Frontal & 9 & 2,2 & $(1,13-4,02)$ \\
\hline Colisão Traseira & 41 & 9,8 & $(7,27-12,97)$ \\
\hline Engavetamento & 2 & 0,5 & $(0,13-1,71)$ \\
\hline Queda de Veículo & 1 & 0,2 & $(0,04-1,33)$ \\
\hline Queda de Moto & 32 & 7,6 & $(5,44-10,55)$ \\
\hline Queda de Passageiro & 9 & 2,2 & $(1,13-4,02)$ \\
\hline
\end{tabular}

* IC - Intervalo de Confiança de 95\%.

Tabela 3. Caracterização dos acidentes de trânsito não fatais segundo o cenário da ocorrência. Maringá, 2013.

\begin{tabular}{|c|c|c|c|}
\hline Variáveis & $\mathbf{N}$ & $\%$ & $95 \%$ IC* \\
\hline \multicolumn{4}{|l|}{ Dia da Semana $(n=420)$} \\
\hline Domingo & 44 & 10,5 & $(7,89-13,77)$ \\
\hline Segunda-feira & 62 & 14,8 & $(11,68-18,47)$ \\
\hline Terça-feira & 57 & 13,6 & $(10,62-17,17)$ \\
\hline Quarta-feira & 61 & 14,5 & $(11,47-18,21)$ \\
\hline Quinta-feira & 64 & 15,2 & $(12,11-18,98)$ \\
\hline Sexta-feira & 63 & 15,0 & $(11,90-18,73)$ \\
\hline Sábado & 69 & 16,4 & $(13,19-20,27)$ \\
\hline \multicolumn{4}{|c|}{ Horário da Ocorrência $(n=420)$} \\
\hline Manhã (07:00 às 13:00) & 128 & 30,5 & $(26,26-35,03)$ \\
\hline Tarde (13:00 às 19:00) & 156 & 37,1 & $(32,65-41,86)$ \\
\hline Noite (19:00 às 00:00) & 104 & 24,8 & $(20,87-29,10)$ \\
\hline Madrugada (00:00 às 07:00) & 32 & 7,6 & $(5,44-10,55)$ \\
\hline \multicolumn{4}{|c|}{ Atendimento pré-hospitalar $(n=414)$} \\
\hline Sim & 246 & 59,4 & $(54,62-64,04)$ \\
\hline Não & 168 & 40,6 & $(35,95-45,37)$ \\
\hline \multicolumn{4}{|l|}{ Hospitalização ( $n=410)$} \\
\hline Hospitais públicos & 4 & 1,0 & $(0,38-2,48)$ \\
\hline Hospitais privados & 239 & 58,3 & $(53,46-62,96)$ \\
\hline Não hospitalizado & 167 & 40,7 & $(36,08-45,55)$ \\
\hline
\end{tabular}

* IC - Intervalo de Confiança de 95\%. 


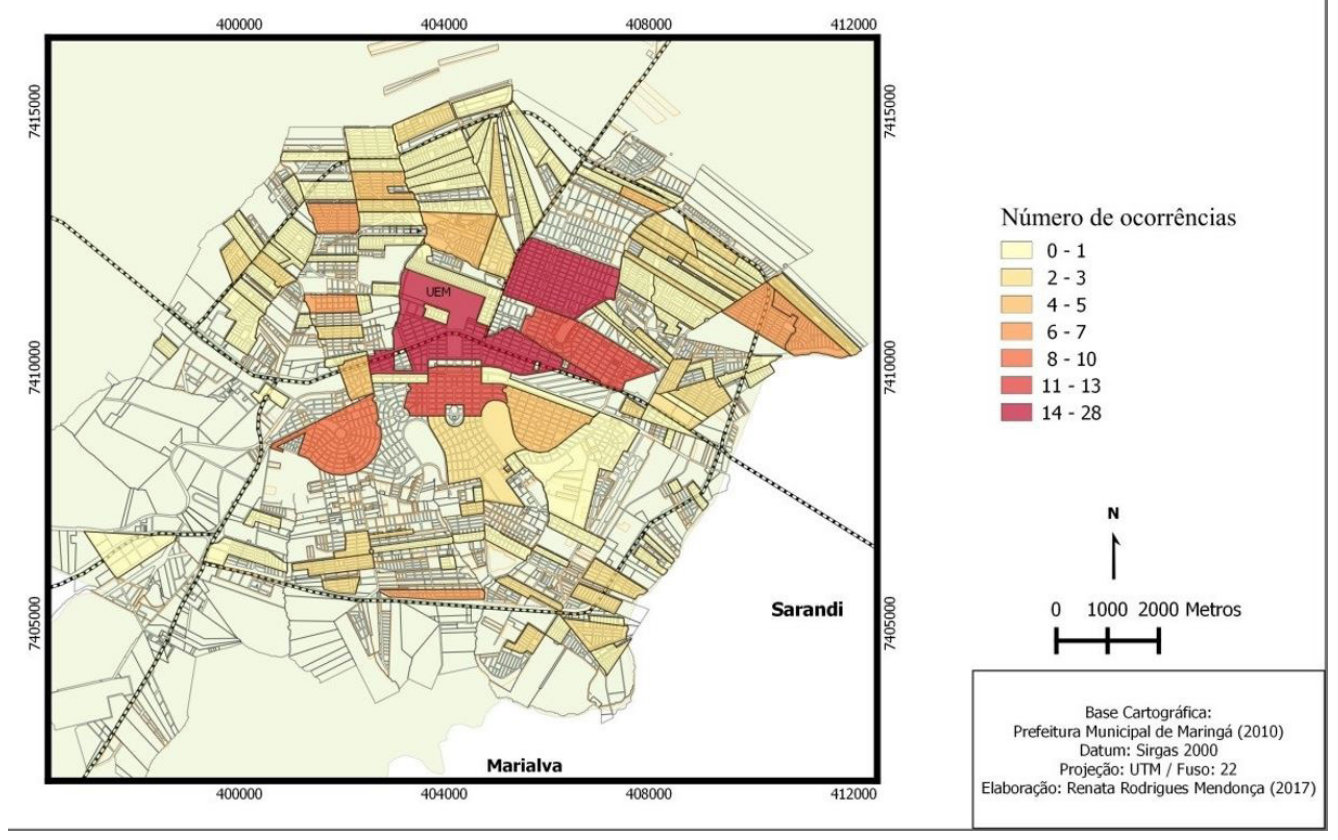

Figura 1. Mapa de distribuição dos acidentes de trânsito para o ano de 2013, Maringá-PR, Brasil.

\section{DISCUSSÃO}

A literatura, de forma geral, apresenta os homens como o sexo predominante para os acidentes de trânsito ${ }^{2,4,7,8}$. Neste estudo, os resultados também os revelaram com maior vulnerabilidade como vítimas não fatais e hospitalizadas em consequência das lesões resultantes. Alguns fatores, como a maior exposição dos homens no trânsito, influenciam social e culturalmente para que assumam maiores riscos ao conduzir veículos ${ }^{8}$.

$O$ fato de jovens adolescentes e adultos jovens estarem mais envolvidos em acidentes não fatais reforça os achados de outros estudos que associaram o envolvimento destas faixas etárias com os acidentes de trânsito ${ }^{4,6-8}$. Acredita-se que a sensação de liberdade, a que o jovem contemporâneo está exposto, pode gerar uma necessidade de experimentar novos limites, que, por vezes, culminam na associação de álcool e direção, excesso de velocidade e manobras perigosas que resultam no expressivo número de vítimas envolvidas em acidentes desta natureza ${ }^{8}$.

Os AT estão relacionados também com a imprudência dos jovens menores de idade que não possuem carteira de habilitação, dirigem há pouco tempo e não têm domínio sobre as leis de trânsito. A partir desta realidade, um estudo qualitativo investigou a percepção do risco de acidente de trânsito entre jovens e verificou que, além do risco envolvendo a intenção de correr e beber há o fator do desconhecimento das leis e suas consequências ${ }^{14}$.

No que se refere ao grau de escolaridade das vítimas, a maior parte tinha oito ou mais anos de estudos, ou seja, possui um nível considerável de formação, levando-nos a entender que são pessoas relativamente instruídas para interpretar e compreender as normas de trânsito. Foram encontrados resultados semelhantes em um estudo realizado no Distrito Federal, onde $28,6 \%$ das vítimas atendidas em razão de acidentes de trânsito tinham oito ou mais anos de estudo ${ }^{15}$.

A motocicleta foi o meio de transporte mais prevalente na ocorrência de acidentes. Apesar de este estudo não verificar a associação entre faixa etária e tipo de veículo, diversos estudos confirmam maior vulnerabilidade de jovens condutores de motocicletas ${ }^{16-19}$ Nos últimos anos, 0 uso da motocicleta tem se modificado, quer por influência de fatores culturais e socioeconômicos quer pelas vantagens desse tipo de veículo em relação aos automóveis: menor custo de aquisição, 
de manutenção, tamanho reduzido que facilita deslocamentos, mesmo em congestionamento. O veículo de duas rodas é também crescentemente utilizado como meio de trabalho. Isto resulta no aumento do número de motocicletas no País e, consequentemente, na vulnerabilidade e exposição ao risco de acidentes dos usuários, tornando-se importante causa de incapacitação física ou morte ${ }^{20}$.

No Paraná, o número de motocicletas apurado em dezembro de 2008 pelo Detran foi de 710.856. Em 2015, já chegavam a 1.002.317, ou seja, houve um crescimento da frota de motocicletas de aproximadamente $41 \%{ }^{5}$.

De acordo com a Associação Brasileira dos Fabricantes de Motocicletas, Ciclomotores, Motonetas, Bicicletas e Similares, as dificuldades enfrentadas para manter o trânsito seguro estão relacionadas a transtornos como estresse, descumprimentos dos códigos de trânsito e situações alheias ao controle, que acabam por prejudicar o condutor durante o seu deslocamento ${ }^{21}$.

A parte frontal do veículo foi a que mais sofreu danos, que é quando ocorre frente a frente e os veículos seguem na mesma direção em sentidos opostos. $\mathrm{O}$ tipo de acidente mais frequente neste estudo foi o abalroamento transversal que é o tipo de acidente em que a colisão ocorre transversalmente, quando os veículos transitam em direções que se cruzam, ortogonal ou obliquamente ${ }^{22}$

Este estudo revelou que a maior parte das ocorrências de acidentes de trânsito foi atendida pelo Serviço Integrado de Atendimento ao Trauma em Emergências (SIATE). Este resultado corrobora achados de um estudo realizado em Curitiba em que $75 \%$ dos atendimentos das vítimas e transporte ao serviço de emergência foram realizados pelo SIATE ${ }^{23}$.

De acordo com os dados registrados no presente estudo, a Santa Casa de Maringá foi o local onde foi atendida a maior parte das vítimas. No Brasil, em 2011, foram registradas 973.015 internações hospitalares por causas externas, representando 8,6\% de todas as internações realizadas nos serviços próprios e conveniadas ao SUS. Desse montante, $15,8 \%$, por acidentes de transporte terrestre (ATT) ${ }^{24}$.

As hospitalizações por acidentes com motocicleta foram as que mais cresceram, chegando a $366,1 \%$ nos últimos 14 anos. No ano de 2012, estas ocuparam mais da metade das causas das internações por acidentes de trânsito registrados no SUS ${ }^{25}$.

Estudo realizado em Uberaba-MG apontou que a maior parte das readmissões está relacionada às vítimas de acidentes com motocicleta. Elas ocorrem até 30 dias após a alta hospitalar. Grande parte das reinternações é devido à necessidade de continuar a avaliação terapêutica ${ }^{26}$.

Em relação ao dia da semana, independentemente do tipo do acidente, neste estudo, os AT transcorreram com frequência regular no decorrer da semana com leve incremento no sábado, o que foi conflitante aos achados de outros autores que apontaram os finais de semana (sexta-feira e sábados) com maior incidência, o que pode ser justificado pelo elevado número de eventos festivos ou de entretenimento e lazer ocorridos nesses dias ${ }^{27}$.

No que se refere ao turno de ocorrência dos AT, houve maior prevalência no período vespertino seguido do matutino, assim como em um estudo realizado em Picos (PI). Contraposto ao que outros autores encontraram, quando registraram um aumento do número de atendimentos no horário noturno se comparado ao diurno ${ }^{28,29}$. Acredita-se que a maior ocorrência nesses períodos é decorrente de acidentes de trabalho, já que os horários em que aconteceram são horários de deslocamento para o trabalho ou às instituições educacionais e seus respectivos retornos para o lar. À medida que as horas vão passando, o acúmulo de cansaço, influências climáticas, exigências, pressões e cobranças, ansiedade e preocupações desgastam o estado físico e mental das pessoas ${ }^{30}$.

Os resultados revelam que os condutores possuíam 10 anos ou mais de habilitação, diferente do que foi encontrado em outros estudos, que apontam motoristas mais novos como principais envolvidos em acidentes graves e fatais. Em média, cada ano adicional da Carteira Nacional de Habilitação $(\mathrm{CNH})$ aumenta a probabilidade de infrações. Isto pode ser caracterizado pelo fato de o condutor sentir-se mais experiente e seguro, acreditando ter mais controle sobre a situação, gerando menos medo e se arriscando mais ${ }^{28}$. 
O mapa por local de incidência de acidentes não fatais serve, principalmente, para mostrar áreas importantes de alto risco, além de identificar o possível local de atendimento pré-hospitalar dessas vítimas. Neste estudo, as incidências de AT se concentraram no centro municipal, em horários considerados de maior deslocamento de pessoas para ir ou vir do trabalho, ou seja, o elevado número de acidentes pode estar diretamente relacionado ao intenso tráfego gerado pelas atividades comerciais, e financeiras ali concentradas, sendo diferente dos achados de outros autores, que estabeleceram uma relação de lazer e entretenimento nos períodos noturno e madrugada, além do consumo de bebidas alcoólicas 14,15,20,22,31.

A dimensão espacial nos estudos de acidentes de trânsito consiste em um importante instrumento para compreensão da dinâmica de eventos como AT, indicando áreas prioritárias para a intervenção ${ }^{32}$. Autores explicam a relevância da espacialização dos acidentes de trânsito por esta fornecer subsídios para o planejamento e execução de políticas públicas, aumentando sua eficácia e eficiência na redução e prevenção desses agravos ${ }^{31-33}$.

No que se refere às políticas públicas na prevenção de AT, no ano de 2011, o Departamento Nacional de Trânsito (Denatran) do Ministério das Cidades e o Ministério da Saúde lançaram Pacto Nacional pela Redução de Acidentes no Trânsito - Pacto pela Vida. Tendo por objetivo mobilizar a sociedade e reunir ações para diminuir os altos índices de acidentes no trânsito, este está enquadrado na meta firmada com a Organização Mundial da Saúde. Preconizada pela Assembleia Geral das Nações Unidas para a "Década de Ações para a Segurança no Trânsito" (2011-2020), este prevê uma redução em até 50\% das mortes ocasionadas pela violência no trânsito nos próximos 10 anos $^{34}$

Dentre os achados principais deste estudo, prevaleceram os acidentes de trânsito na região central, no período diurno, cuja maioria das vítimas era de jovens do sexo masculino e motociclistas. Essas ocorrências parecem estar associadas ao intenso tráfego existente por questões de deslocamento relacionadas a atividades profissionais e universitárias essencialmente.

A análise espacial de padrões epidemiológicos pode se transformar em um instrumento valioso na avaliação do impacto de processos e estruturas sociais na determinação de eventos de saúde. Conhecer a estrutura e dinâmica espacial permite a caracterização da situação em que ocorrem eventos.

Espera-se, portanto, que este estudo contribua no desenvolvimento de tecnologias para melhoria no monitoramento e educação da população, incluindo medidas de intervenção no sentido de reduzir os índices das ocorrências de violências e acidentes, sobretudo na identificação de pontos críticos de localização dos acidentes e das suas consequências mais graves, como os elevados índices de morbidade e mortalidade entre a população que utiliza os meios de transporte terrestres motorizados.

\section{REFERÊNCIAS}

1. Instituto de Pesquisa Econômica Aplicada. Associação Nacional dos Transportes Públicos. Impacto social e econômico dos acidentes de trânsito nas aglomerações urbanas brasileiras: relatório executivo. Brasília; São Paulo: ANTP; 2003.

2. Cavalcante JDF. Implantação de uma rede de atenção as vítimas de acidentes de trânsito que apresentam como sequela o Transtorno de Estresse Pós-Traumático (TEPT) no município de Igarassu-PE [monografia]. Recife: Fundação Oswaldo Cruz; 2012. [citado em 2017 Out 03]. Disponível em: http://www.cpqam.fiocruz. br/bibpdf/2012cavalcante-jf.pdf

3. Instituto de Pesquisa Econômica Aplicada. Departamento Nacional de Trânsito. Impactos sociais e econômicos dos acidentes de trânsito nas rodovias brasileiras: relatório executivo. Brasília: DENATRAN; 2015.

4. Brasil. Ministério da Saúde. Portal do Brasil: vigilância de violências e acidentes, 2002 e 2010. Brasília, DF; 2009. $154 \mathrm{p}$.

5. Departamento Nacional de Trânsito. Evolução de receitas e despesas: 1998 a 2014. Brasília: Denatran; 2015.

6. Brasil. Ministério da Saúde. Viva: vigilância de violências e acidentes: 2006 e 2007. Brasília., DF; 2009. 154 p.

7. Cyrillo RMZ, Dalri MCB, Silva Canini SRM, Carvalho EC, Lourencini RR. Diagnósticos de enfermagem em vítimas de trauma atendidas em um serviço pré-hospitalar avançado móvel. Rev. Eletr. Enf. 2009;11(4):8119. http://dx.doi.org/10.5216/ree.v11i4.33235. 
8. Ascari RA, Chapieski CM, da Silva OM, Frigo J. Perfil epidemiológico de vítimas de acidente de trânsito. Rev. enferm. UFSM. 2013;3(1):112-21.

9. Mascarenhas MDM, Malta DC, Silva MMA, Lima CM, Carvalho MGO, Oliveira VLA. Violência contra a criança: revelando o perfil dos atendimentos em serviços de emergência, Brasil, 2006 e 2007. Cad Saude Publica. 2010;26(2):347-57. http://dx.doi.org/10.1590/S0102-311X2010000200013. PMid:20396849.

10. Waiselfisz JJ. Mapa da violência 2014. Os jovens do Brasil. São Paulo: Sangari; 2014.

11. Bacchieri G, Barros AJ. Acidentes de trânsito no Brasil de 1998 a 2010: muitas mudanças e poucos resultados. Rev Saude Publica. 2011;45(5):949-63. http://dx.doi.org/10.1590/S0034-89102011005000069. PMid:21953026.

12. Matsumoto PSS, Flores EF. Estatística espacial na geografia: um estudo dos acidentes de trânsito em Presidente Prudente-SP. Geografia em Atos. 2012; 12(1):95-113.

13. Costa DCS, Moraes RM. Análise dos acidentes de trânsito utilizando técnicas de análise espacial. SHEWC. 2009;9(1):81-4.

14. Benincasa $M$, Rezende $M M$. Percepção de fatores de risco e de proteção para acidentes de trânsito entre adolescentes. Bol Psicol. 2006;56(125):241-56.

15. Malta DC, Silva MMA, Barbosa J. Violências e acidentes, um desafio ao Sistema Único de Saúde. Ciênc. saúde colet. 2012;17(9):2220-1. http://dx.doi.org/10.1590/S1413-81232012000900001.

16. Mello Jorge MHP, Adura FE. Álcool e direção veicular. Rev. USP.2013;96:23-36.

17. Paixão LMMM, Gontijo ED, Drumond EDF, Friche AADL, Caiaffa WT. Acidentes de trânsito em Belo Horizonte: o que revelam três diferentes fontes de informações, 2008 a 2010. Rev Bras Epidemiol. 2015;18(1):108-22. http://dx.doi.org/10.1590/1980-5497201500010009. PMid:25651015.

18. Moysés SJ. Determinação sociocultural dos Acidentes de transporte Terrestre (ATT). Cien Saude Colet. 2012;17(9):2237-45. http://dx.doi.org/10.1590/S1413-81232012000900005. PMid:22996873.

19. Oliveira RMV. Perfil das vítimas de acidentes motociclísticos atendidos em um hospital público de Campina Grande-PB [monografia]. Campina Grande: Universidade Estadual da Paraíba; 2014.

20. Associação Brasileira de Ciclomotores. Estatística de produção e vendas de motocicletas [Internet]. São Paulo: Abraciclo; 2012 [citado em 2017 Out 03]. Disponível em: http://www.abraciclo.com.br

21. Oliveira NLBD, Sousa RMCD. Risco de lesões em motociclistas nas ocorrências de trânsito. Rev Esc Enferm USP. 2012 out;201246(5):1133-40. http://dx.doi.org/10.1590/S0080-62342012000500014. PMid:23223729.

22. Andrade SSCDA, Sá NNBD, Carvalho MGOD, Lima CM, Silva MMAD, Moraes Neto OL, et al. Perfil das vítimas de violências e acidentes atendidas em serviços de urgência e emergência selecionados em capitais brasileiras: Vigilância de Violências e Acidentes, 2009. Epidemiol Serv Saude. 2012;21(1):21-30. http:// dx.doi.org/10.5123/S1679-49742012000100003.

23. Franco Di Credo P, Felix JVC. Perfil dos pacientes atendidos em um hospital de referência ao trauma em Curitiba: implicações para a enfermagem. Cogitareenferm.2012;17(1):126-31.

24. Mascarenhas MDM, Barros MBDA. Evolução das internações hospitalares por causas externas no sistema público de saúde-Brasil, 2002 a 2011. Epidemiol Serv Saude. 2015;24(1):19-29. http://dx.doi.org/10.5123/ S1679-49742015000100003.

25. Waiselfisz JJ. Mapa da violência 2013. Os jovens do Brasil. São Paulo: Sangari; 2013. 170 p.

26. Paiva L, Monteiro DAT, Pompeo DA, Ciol MA, Dantas RAS, Rossi LA. Readmissões por acidentes de trânsito em um hospital geral. Rev. Latino-Am. Enfermagem. 2015;23(4):693-9. http://dx.doi.org/10.1590/01041169.0242.2623.

27. Andrade ML, Lima MA, Silva CHC, Caetano JA. Acidentes de motocicleta: características das vítimas e dos acidentes em hospital de Fortaleza-CE, Brasil. Rev. Rene. 2009;10(4):52-9.

28. Almeida RLF, Bezerra Filho JG, Braga JU, Magalhaes FB, Macedo MCM, Silva KA. Via, homem e veículo: fatores de risco associados à gravidade dos acidentes de trânsito. Rev Saude Publica. 2013;47(4):718-31. http://dx.doi.org/10.1590/S0034-8910.2013047003657. PMid:24346663.

29. Golias AR, Caetano R. Acidentes entre motocicletas: análise dos casos ocorridos no estado do Paraná entre julho de 2010 e junho de 2011. Cien Saude Colet. 2013;18(5):1235-46. http://dx.doi.org/10.1590/ S1413-81232013000500008. PMid:23670451.

30. Soares LS, Sousa DACM, Machado ALG, Silva GRF. Caracterização das vítimas de traumas por acidente com motocicleta internadas em um hospital público. Rev. enferm. UERJ. 2015;23(1):115-21.

31. Melo WA, Alarcão A, de Oliveira A, Pelloso SM, Carvalho MDB. Age-related risk factors with nonfatal traffic accidents in urban areas in Maringá, Paraná, Brazil. Traffic Inj Prev. 2016;18(2):157-63. http://dx.doi.org/ 10.1080/15389588.2016.1235786. PMid:27624544. 
32. Marín-León L, Belon AP, Barros MBDA, Almeida SDDM, Restitutti MC. Tendência dos acidentes de trânsito em Campinas, São Paulo, Brasil: importância crescente dos motociclistas. Cad Saude Publica. 2012;28(1):3951. http://dx.doi.org/10.1590/S0102-311X2012000100005. PMid:22267064.

33. Souza VR, Cavenaghy S, Alves JED, Magalhães MAFM. Análise espacial dos acidentes de trânsito com vítimas fatais: comparação entre o local de residência e de ocorrência do acidente no Rio de Janeiro. R. bras. Est. Pop. 2008;25(2):353-64. http://dx.doi.org/10.1590/S0102-30982008000200010.

34. Organização das Nações Unidas. Década de Ação pela Segurança no Trânsito (2011-2020) [Internet]. New York: ONU; 2017. [citado em 2017 Out 03]. Disponível em: https://nacoesunidas.org/campanha/ segurança-transtito/. 